Walter Salzburger $\cdot$ Axel Meyer

\title{
The species flocks of East African cichlid fishes: recent advances in molecular phylogenetics and population genetics
}

Published online: 20 April 2004

\begin{abstract}
With more than 3,000 species, the fish family Cichlidae is one of the most species-rich families of vertebrates. Cichlids occur in southern and central America, Africa, Madagascar, and India. The hotspot of their biodiversity is East Africa, where they form adaptive radiations composed of hundreds of endemic species in several lakes of various sizes and ages. The unparalleled species richness of East African cichlids has been something of a conundrum for evolutionary biologists and ecologists, since it has been in doubt whether these hundreds of species arose by allopatric speciation or whether it is necessary to invoke somewhat less traditional models of speciation, such as micro-allopatric, peripatric, or even sympatric speciation or evolution through sexual selection mediated by female choice. Ernst Mayr's analyses of these evolutionary uniquely diverse species assemblages have contributed to a more direct approach to this problem and have led to a deeper understanding of the patterns and processes that caused the formation of these huge groups of species. We review here recent molecular data on population differentiation and phylogenetics, which have helped to unravel, to some extent, the patterns and processes that led to the formation and ecological maintenance of cichlid species flocks. It is becoming apparent that sexually selected traits do play an important role in speciation in micro-allopatric or even sympatric settings. Species richness seems to be roughly correlated with the surface area, but not the age, of the lakes. We observe that the oldest lineages of a species flock of cichlids are often less species-rich and live in the open water or deepwater habitats. While the species flocks of the Lake Malawai and the Lake Victoria areas were shown to be mono-
\end{abstract}

Dedicated to Prof. Ernst Mayr

W. Salzburger · A. Meyer (

Lehrstuhl für Zoologie und Evolutionsbiologie,

Fachbereich Biologie,

Universität Konstanz,

78457 Konstanz, Germany

e-mail: axel.meyer@uni-konstanz.de

Tel.: +49-7531-884163

Fax: +49-7531-883018 phyletic, the cichlid assemblage of Lake Tanganyika seems to consist of several independent species flocks. Cichlids emerge as an evolutionary model system in which many fundamental questions in evolution and ecology can be tested successfully, yet for other fish species flocks the relative importance of alternative mechanisms of speciation is likely to differ from that in cichlid fish.

\section{Introduction}

Cichlid fishes are tropical freshwater fish that are unsurpassed by any other group of vertebrate in terms of their sheer number of species $(\sim 3,000)$, variety of body shapes, assortment of coloration, behavioral diversity, and degree of trophic and ecological specialization (see Fryer and Iles 1972; Coulter; Meyer 1993; Stiassny and Meyer 1999; Kornfield and Smith 2000; Schluter 2000; Kocher 2004). Since the publication of the first reports on the East African fish fauna at the end of the nineteenth century (Boulenger 1898), the exceptional diversity of fishes in the family Cichlidae has attracted the attention of evolutionary biologists. Cichlids were viewed by some as an enigmatic, hard-to-explain, aberrantly species-rich group. Yet, their exuberant variation made them important models and textbook examples for rapid speciation and diversification (Fryer and Iles 1972; Stiassny and Meyer 1999; Kornfield and Smith 2000; Schluter 2000; Kocher 2004).

Molecular phylogenetic analyses (Zardoya et al. 1996; Streelman et al. 1998; Farias et al. 2000, 2001; Sparks 2004) have revealed that the phylogenetic relationships among the major lineages of cichlids are consistent with an initially Gondwanaland distribution, with the Indian and Malagasy representatives forming the most basal lineages and the reciprocally monophyletic African and American lineages being sister groups-a distributional pattern that is congruent with models of vicariance biogeography rather than overseas dispersal (Fig. 1). Only about a dozen extant species represent the most basal 


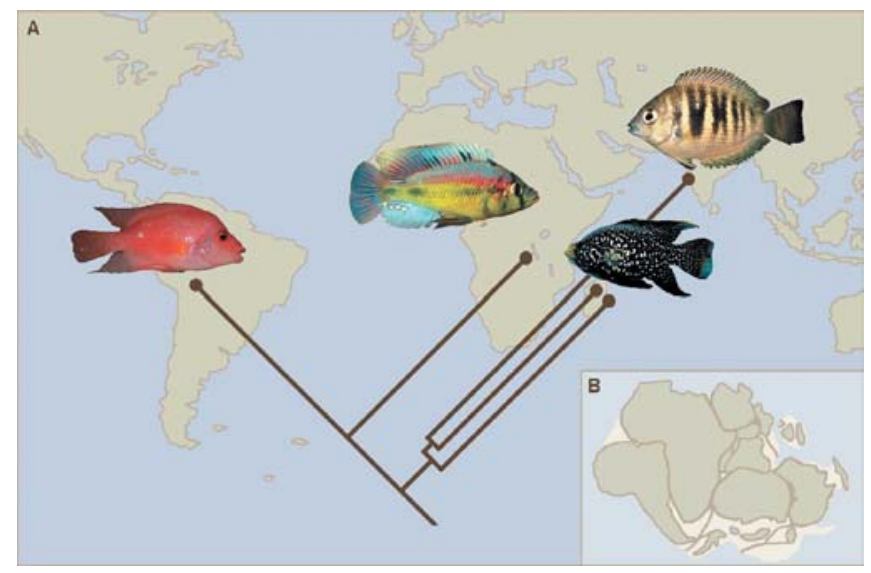

Fig. 1A, B Distribution of the Cichlidae. A The distributional pattern of the cichlids, with the representatives from India, Sri Lanka, and Madagascar forming the most basal lineages and the reciprocally monophyletic African and American lineages as sister-groups, is consistent with an initially Gondwanaland distribution (Zardoya et al. 1996; Streelman et al. 1998; Farias et al. 2000, 2001; Sparks 2004). B The supercontinent of Gondwanaland some 200 million years ago $(M Y A)$

paraphyletic lineages of cichlids from India/Sri Lanka and Madagascar, which are the two landmasses that split off first from the supercontinent of Gondwanaland between 165 and 130 million years ago (MYA). The Americas are inhabited by an estimated 400-500 species. Their center of biodiversity is East Africa, where the cichlids inhabit several small and some exceptionally large lakes (as well as rivers) and have formed so-called "species flocks" with sometimes hundreds of endemic species in each of these lakes. By far the greatest diversity of cichlids occurs in East Africa in Lakes Victoria, Malawi and Tanganyika (Fig. 2), where a total of probably more than 1,800 species may occur.

With an age of 9-12 million years, Lake Tanganyika is the oldest of East Africa's Great Lakes (Cohen et al. 1993, 1997), followed by Lake Malawi with a probable age of 2-5 million years (Johnson and Ng'ang'a 1990; Delvaux 1995). Both Lake Tanganyika and Lake Malawi have the shape and characteristics of a typical rift lake, as they are located in the rift between the east African and central African tectonic plate. They are relatively narrow and extremely deep (up to $\sim 1,450 \mathrm{~m}$ in the case of Lake Tanganyika). Lake Victoria, however, the youngest of East Africa's Great Lakes, is a rather shallow lake $(\sim 80 \mathrm{~m}$ maximum depth) that formed between 250,000 and 750,000 years ago (Johnson et al. 1996). Around the size of Ireland (about $68,800 \mathrm{~km}^{2}$ ), Lake Victoria is the world's largest tropical lake and contains 500 or more endemic species of cichlids (Seehausen 1996). Molecular phylogenetic studies suggest that the Lake Victoria "superflock" (Greenwood 1979, 1980, 1984a) includes not only the endemic cichlids of this inland water, but also those of some of its neighboring lakes such as Lakes Albert, Edward, George, Kyoga, and Kivu, and that it is about 100,000 years old (Meyer et al. 1990; Nagl et al. 2000; Seehausen et al. 2003; Verheyen et al. 2003). Lake

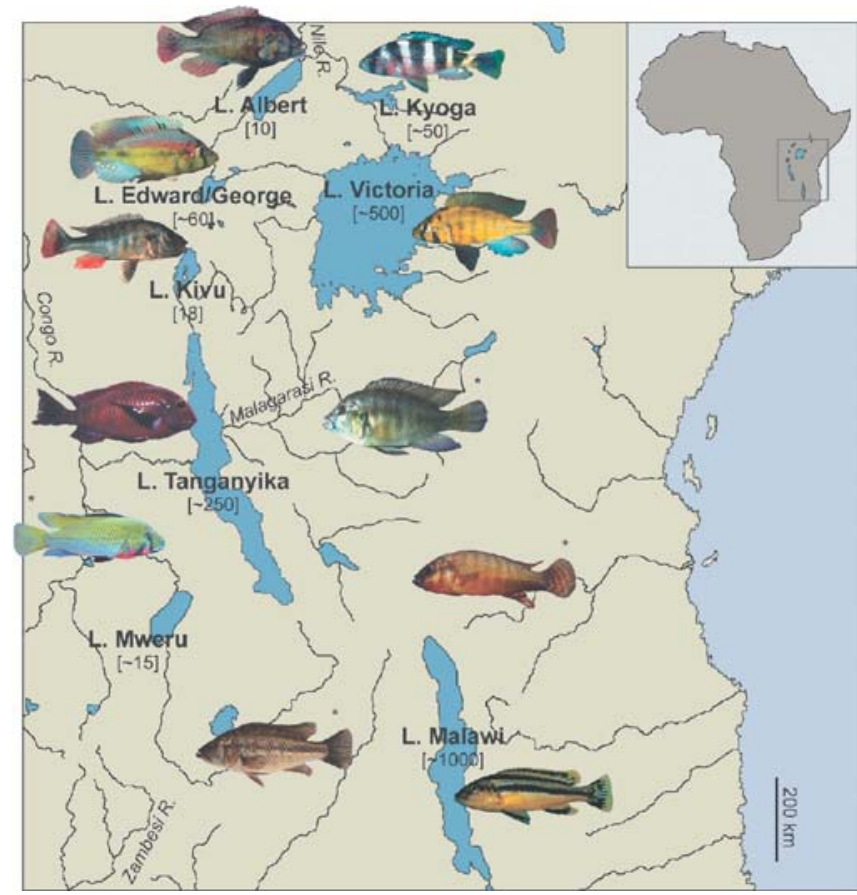

Fig. 2 The cichlids' center of biodiversity is East Africa, where they inhabit the rivers and lakes and have formed species flocks of unparalleled species richness and morphological diversity. More than 2,000 cichlid species are recognized, $80 \%$ of which belong to a single tribe, the Haplochromini. The most species-rich assemblages are found in the East African Great Lakes: Tanganyika, Malawi, and Victoria. More than 200 species live in rivers (four representatives marked with an asterisk are depicted). Estimated species numbers are given in square brackets

Malawi contains 500-700 (some estimates even reach 1,000) cichlid species (Turner et al. 2001), while for Lake Tanganyika "only" about 200-250 species of cichlids are estimated (Snoeks et al. 1994). It should be noted that this number is likely to be an underestimate of the actual number of biological cichlid species in this lake.

\section{Modes of speciation}

Historically, the enormous diversity of the assemblages of cichlid species has been considered a challenge, "the cichlid problem", which was seen, at least by several investigators to question or even contradict traditional models of speciation. Several researchers, including some of the earliest workers on speciation theory (Woltereck 1931; Rensch 1933; Kosswig 1947; Brooks 1950), invoked sympatric speciation models to explain how so many species could arise within one body of water, without obvious barriers to gene flow and thereby genetic population differentiation. Clearly, there is something special about the evolutionary success of cichlid fishes, which might - at least it was seen this way by some researchers - require special explanations. Two of the major issues in the cichlid problem are to explain (1) how such large numbers of species of cichlids, and not of the other 
families of fishes that also inhabit these lakes, could have arisen, and (2) how the species are ecologically maintained without outcompeting each other and driving each other to extinction.

Several factors are believed to be responsible for the diversity of cichlids. One has to do with their specialized anatomy. Cichlids possess two sets of jaws: one shapes the "normal" mouth, to suck, scrape, or bite off bits off food; another "internal" one, which is derived from the 5th gill arch, is in the throat to crush, macerate, slice, or pierce the morsel before it is ingested. The particular organization of the pharyngeal jaw apparatus is a synapomorphy shared by all cichlids (Liem 1973, 1980). The jaws are exceedingly versatile and adaptable; for example, they can change in form even within the lifetime of a single individual (see discussion in Meyer 1990a, 1990b). A second factor has to do with the cichlid's sophisticated breeding behavior and in particular with the various modes of broodcare behavior that are found in the East African lake cichlids (Fryer and Iles 1972; Goodwin et al. 1998; Stiassny and Meyer 1999; Barlow 2000; Kornfield and Smith 2000; Klett and Meyer 2002). More recent studies suggested that sexual selection through female choice of male (nuptial) coloration might also play an important role in the evolution of East African cichlids (Dominey 1984; Meyer 1993; Turner and Burrows 1995; Deutsch 1997; Seehausen and van Alphen 1999; Barlow 2000; Danley and Kocher 2001). Speciation on the basis of sexual selection in East African cichlids has been proposed on the basis of field observations (van Oppen et al. 1998) as well as mate choice experiments in the laboratory (Knight et al. 1998; Seehausen et al. 1999). Further evidence for sexual selection came from the observable breakdown of visual reproductive barriers under monochromatic light conditions or in turbid waters (Seehausen et al. 1997).

\section{Ernst Mayr and speciation in cichlids}

The "cichlid problem" has been, for more than 60 years, a topic that Ernst Mayr has returned to periodically in his writings since he first mentioned it in his landmark book Systematics and the Origin of Species (Mayr 1942). He discussed various aspects of the cichlid problem and suggested that the size and age of a lake might be much more important determinants of (i.e., might be positively correlated with) species number than predation, the prevailing hypothesis of that time (Worthington 1937, 1940). Mayr suggested that predators might have an a posteriori effect, in that "they can exterminate aberrant types" (Mayr 1942, p 272) and would be a "conservative factor by preventing super-specializations, but it is not apparent how they could possibly affect the establishment of discontinuities."

Twenty years ago Mayr (1984) succinctly reviewed the work on fish species flocks in a commentary to a compendium of largely empirical studies (Echelle and Kornfield 1984) and summarized the major open questions about the formation of the species flocks of cichlids thus:
1. Is the presence of hundreds of closely related species within a single lake inconsistent with traditional allopatric speciation modes?

2. Do the species flocks refute the principle of competitive exclusion?

Mayr (1984) went on to outline the deficiencies in the empirical data and the problems that this lack of information presented in terms of answering some of the fundamental problems that the cichlid species flocks pose to evolutionary theory. Reviewing the available literature and analyzing the then state of knowledge, or rather the relative lack of it at that time, Mayr (1984) summarized the three major areas of uncertainty, as follows.

\section{Uncertainty regarding the age of the species flocks and their habitats}

Since the ages of the flocks were still unknown 20 years ago, it was unclear as to whether the flocks really arose at unfeasibly fast rates of speciation that might throw doubt on traditional models of speciation.

2. Uncertainties regarding taxonomy in systematics

Taxonomically, the species flocks were insufficiently known, and in many cases sister group relationships were unclear and entirely based on morphological traits. Many of those were later found to be susceptible to high levels of homoplasy (see below). That most (or all) of these putative species are genuine biological species was not questioned. It was asserted that they are genetically well separated, even if they often are extremely similar morphologically.

3. Uncertainties regarding cladistic analyses Mayr (1984) laments that the-as he, probably rightly,sees it-limitations of cladistic analysis have been reached, given the extreme genetic and morphological similarity of such a large number of species (see also Mayr and Brock 2002). Interestingly, Mayr recognizes that homoplasy and parallelism which are likely observed (but not proven then to be homoplasy rather than synapomorphies) among large sets of closely related species pose a challenge to the phylogenetic reconstruction of evolutionary relationships and, possibly more important, to the investigation of the processes of lineage formation.

The imperfections of analytical techniques as well as the paucity of crucial data were summarized by Mayr (1984), and three major potential causes for the large number of cichlid species were considered:

1. multiple colonization of lake habitats from several lineages of riverine ancestors (questioning the monophyly of these species flocks)

2. amalgamation of smaller lakes and their subflocks into larger species flocks due to rising lake levels

3. intralacustrine speciation by one of several possible mechanisms of speciation. 
Mayr (1942) as well as Rensch (1933), but not Kosswig (1947), initially favored explanations such as multiple colonization and fusions of smaller flocks into larger ones as likely partial explanations for the emergence of the extraordinarily large species flocks of cichlids. However, Mayr later felt that intralacustrine speciation was responsible for the formation of these large species assemblage (Mayr 1984).

Intralacustrine speciation, according to Mayr (1984), can be envisioned to work in several ways. Partial separation-through major lake level fluctuations-of large and deep lake basins such as those of Lakes Tanganyika or Malawi into several sub-basins may promote allopatric speciation. Allopatric speciation might also work if a large lake basin is not divided into smaller ones. Cichlid fishes are known for their pronounced philopatry and their, in general, low dispersal abilities, which, according to Mayr (1984), promotes allopatric intralacustrine speciation.

Moreover, most cichlids are very tightly linked to particular substrate types, e.g., rocky substrate or sandy habitats, due to extreme food specialization. The mosaic distribution of different types of habitats along the shores of the large African lakes provides ample opportunity for population subdivision and are effective barriers to gene flow.

Finally, the spatial distribution of spawning sites is discontinuous, which, in conjunction with, and as a byproduct of, small effective population sizes would promote the rapid evolution of premating isolating mechanisms. Mayr (1984) suggested that spawning site fidelity might be an important contributing factor to speciation in the species flocks of East African cichlids. This suggestion has not really been followed up so far. Mayr's contention is that speciation is largely a non-adaptive byproduct of isolation. Dobzhansky (1937), on the other hand, argued that during the process of speciation preisolating mechanisms are formed only incompletely in periods of isolation and are completed through reinforcement, through natural selection against intermediate phenotypes (inferiority of hybrids), after contact with neighboring incipient species. Accordingly, morphological as well as ecological differences between these diverging populations would be exacerbated through character displacement.

Mayr (1984) postulated that two sets of factors need to be shown to act in the ecological setting of the African lakes to explain the evolution of their cichlid species flocks, the existence of isolating mechanisms (ecological or behavioral) that would prevent the nascent species from merging with other species, and factors that might be responsible for the facilitation of the evolution of isolating mechanisms in the first place. The great evolutionist always argued against ecological factors and for geographic aspects as major initial driving forces for isolating mechanisms (Mayr 1947, 1963) because he felt that speciation as a byproduct of ecological divergence for incipient species would not be likely, since the niche differences of many nascent species would be too slight for complete reproductive isolation. Based on Dominey (1984) he instead argued that sexual selection might be a stronger force for speciation than ecological factors. Mayr (1984) went on to argue that sexual selection should be regarded as "micro-allopatric" speciation, since rapid evolution of premating isolating mechanisms would have resulted in "mating clusters" of individuals that are spatially somewhat separated.

In the following section we attempt to summarize the major advances of the last 20 years, mostly due to the application of molecular techniques, since the publication of Mayr's (1984) assessment of the "cichlid problem". We review the current knowledge on the phylogenetic relationships and population structure of the cichlid species flocks of the Great Lakes in East Africa and discuss the species flock concept in the light of these hypotheses. We then focus on intralacustrine speciation and the mechanisms by which the unique diversity of cichlids in East Africa might have emerged. We conclude that future evolutionary genomic approaches would greatly advance our understanding of the patterns and processes involved in explosive speciation and adaptive radiation in cichlids, and also in other groups of organisms.

\section{Molecular data and the East African cichlid species flocks}

\section{Lake Victoria}

The cichlid species assemblage of Lake Victoria (see Fig. 2) was among the first endemic faunas to be studied by means of molecular phylogenetic tools (Sage et al. 1984; Meyer et al. 1990). The study of Meyer et al. (1990) was based on a segment of the mitochondrial cytochrome $b$ gene, where no variation at all was found, and the mitochondrial DNA control region, the fastest evolving section of the mitochondrial genome. Among other findings, this paper established the monophyly of the Lake Victoria region cichlid species flock. However, Meyer et al. (1990) did not include specimens of all the neighboring lakes of Lake Victoria, which have been grouped into a "superflock" of closely related species based on morphological grounds (Greenwood 1973, 1979, 1980). Our more recent phylogeographic study proposed an origin of the "superflock" (now including the cichlid faunas from Lakes Victoria, Albert, Edward, George, Kyoga, and Kivu) from Lake Kivu endemics and revealed that the Lake Victoria cichlid assemblage is technically diphyletic (Verheyen et al. 2003). In addition, the age of the "superflock" has been discussed in detail (Meyer et al. 1990; Fryer 1997, 2001, 2004; Booton et al. 1999; Nagl et al. 2000; Sturmbauer et al. 2001; Seehausen 2002; Seehausen et al. 2003; Verheyen et al. 2003), particularly after geological data suggested that the entire lake basin dried out completely between 15,600 and 14,700 years ago (Johnson et al. 1996). Molecular phylogenetic studies agree that the age of Lake Victoria's cichlid fauna is less than 200,000 years (Meyer et al. 1990; Nagl et al. 2000), and is 
probably about 100,000 years (Verheyen et al. 2003; Salzburger et al. 2004). Due to the extremely young age of the assemblage, the phylogenetic inference among the cichlid species in the superflock is rather difficult, and species often share mitochondrial haplotypes (Verheyen et al. 2003; R.O. Abila et al., unpublished). Also in noncoding regions of the nuclear DNA the persistence of polymorphisms was detected among Lake Victoria cichlids (Nagl et al. 1998).

\section{Lake Malawi}

From the almost 1,000 species of Lake Malawi only a relatively small proportion have been subjected to phylogenetic analyses (Meyer et al. 1990, 1996b; Kocher et al. 1993; Moran et al. 1994; Reinthal and Meyer 1997; Albertson et al. 1999; Shaw et al. 2000; Takahashi et al. 2001a; Allender et al. 2003). In a study based on two mitochondrial gene segments and including specimens from all main lineages identified so far, representatives of the pelagic genera Rhamphochromis and Diplotaxodon were resolved as sister group to a clade formed by the rock-dwelling "mbuna" cichlids, the "non-mbuna" cichlids, Copadichromis virginalis, and the riverine representative Astatotilapia calliptera (Meyer et al. 1996b; Shaw et al. 2000). The reconstruction of the relationship between Lake Malawi cichlids is made more complicated by the persistence of ancestral polymorphisms across species (Moran and Kornfield 1993), which reflects the young age of the species flock. Recent studies using the AFLP method to overcome this problem have provided phylogenetic hypotheses for larger subgroups of the mbuna cichlids (Albertson et al. 1999; Allender et al. 2003). Population-genetic analyses based on microsatellite markers have also been successfully applied in Lake Malawi mbuna cichlids and it has been shown that deep waters and sandy stretches may act as strong barriers to gene flow (van Oppen et al. 1997; Arnegard et al. 1999; Markert et al. 1999). Sometimes a habitat discontinuity of only about $35 \mathrm{~m}$ seems sufficient to isolate two populations (Rico and Turner 2002).

\section{Lake Tanganyika}

The phylogeny of the Lake Tanganyika cichlid assemblage is the best understood, which is-at least to some extent-facilitated by the greater age of the lake and its species assemblage. This leads to more pronounced differences in genetic diversity (Sturmbauer and Meyer 1992; Salzburger et al. 2002a) as well as in morphology, ecology, and behavior of its species (Fryer and Iles 1972; Greenwood 1984b; Poll 1986), making phylogenetic inference feasible. The cichlids of Lake Tanganyika were grouped into 12 eco-morphologically distinct tribes (Poll 1986), whereas the monophyletic species flocks of Lakes Victoria and Malawi consist of representatives of one of these tribes only, the Haplochromini. The first attempts to reconstruct the evolution of the species flock using allozyme data (Nishida 1991) identified several ancient lineages that are basal to the substrate-spawning Lamprologini plus the mouthbrooding "H-lineage," which led to the notion that Lake Tanganyika is an evolutionary reservoir for old African cichlid lineages (Nishida 1991). Subsequent work based on mitochondrial DNA sequences (see, e.g., Sturmbauer and Meyer 1992; Sturmbauer et al. 1994, 2003; Kocher et al. 1995; Salzburger et al. 2002a; Baric et al. 2003; Koblmüller et al. 2004) and on SINE insertion patterns (see, e.g., Takahashi et al. 1998) were in astonishing agreement-with the exception of only a handful of species that were suggested to be in need of reassignment to other tribes-with the reciprocal monophyly of the eco-morphologically defined tribes of Poll (1986). Unlike the monophyletic haplochromine species flocks of Lake Malawi and the Lake Victoria region, the species assemblage of Lake Tanganyika turned out to be oligophyletic, i.e., several (riverine) lineages are likely to have entered the lake habitat after its formation and radiated in parallel (Salzburger et al. 2002a). While more ancestral lineages combine a handful of species only, the substrate-spawning Lamprologini ( 100 species) and the Tanganyikan mouthbrooders ( $\sim 80$ species $)$ [the "H-lineage" of Nishida (1991) but excluding the goby-like Eretmodini] are relatively species-rich (see Fig. 3). However, no comprehensive nuclear DNA phylogeny exists so far for the Lake Tanganyika cichlid assemblage.

\section{The species flock concept in light of molecular phylogenetic analyses}

A species flock (or species swarm) is generally referred to as a monophyletic assemblage of closely related species that coexist in the same area (Greenwood 1984a; Mayr 1984), and it was Mayr (1942) who closely associated the two concepts of explosive speciation and species flock. Three criteria for a species flock and its members were recognized in an ichthyologic context:

1. a geographical circumscription

2. a high level of endemicity

3. a close phyletic relationship (Greenwood 1984a).

For most lacustrine species flocks, the lake habitat itself resembles the geographical circumscription. That the confines of a single lake circumscribe the species flock is not the case for the Lake Victoria region superflock, which combines the species assemblages of Lakes Victoria, Albert, Edward, George, Kyoga, Kivu and several smaller lakes in the region (Greenwood 1973, 1979, 1980; Verheyen et al. 2003). However, for the Lake Victoria superflock a clear geographic boundary is also evident that, in this case, includes more than one body of water and rivers as well as lakes (Nagl et al. 2000; Seehausen et al. 2003; Verheyen et al. 2003). We note that the reverse conclusion, that all cichlid species of these lakes strictly belong to the superflock, is not valid; there are several 


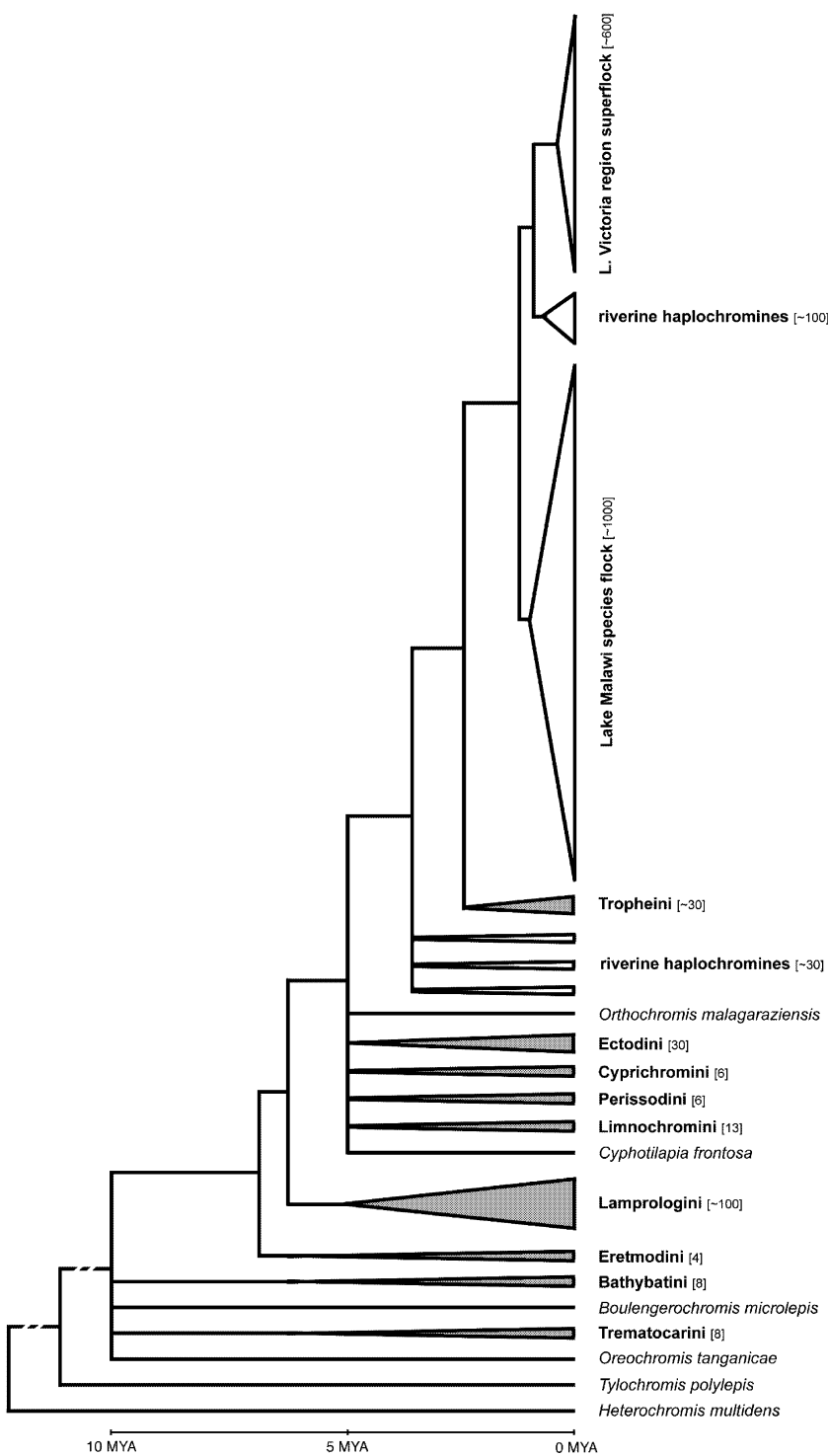

Fig. 3 Molecular phylogeny of the East African cichlids (combined after Klett and Meyer 2002; Salzburger et al. 2002a; Verheyen et al. 2003). Within the Lake Tanganyika assemblage, several sub-radiations can be delineated (depicted in gray), with the substratespawning Lamprologini being the most species-rich tribe (Poll 1986). Several cichlid lineages have secondarily left Lake Tanganyika (Sturmbauer et al. 1994; Salzburger et al. 2002a), and also the common ancestor of the East African riverine haplochromines, the Tanganyikan Tropheini as well as the species flocks of Lake Malawi and the Lake Victoria region seem to be of Lake Tanganyika origin (Nishida 1991; Kocher et al. 1995; Salzburger et al. 2002a). MYA million years ago

more ancestral haplochromine species in these lakes, such as Astatoreochromis alluaudi and Pseudocrenilabrus multicolor in Lake Victoria, Haplochromis gracilior in Lake Kivu and Haplochromis spp. in Lake Edward/George that do not belong to the superflock (Nagl et al. 2000; Salzburger et al. 2002a; Verheyen et al. 2003). Also, several species of tilapia are found in the water-bodies of this area (Fryer and Iles 1972), which are rather distantly related to the haplochromines and are ultimately of WestAfrican origin (Klett and Meyer 2002).

For the Lake Tanganyika assemblage, or at least for some Tanganyikan tribes, the criterion of a geographical circumscription is problematic, as several lineages of Tanganyikan origin left the lake habitat secondarily and their descendants are now distributed over large parts of the African continent (Sturmbauer et al. 1994; Salzburger et al. 2002a, 2002b). Also the ancestor of the species flocks of Lake Malawi and the Lake Victoria region is likely to be of Tanganyikan origin (Kocher et al. 1993; Salzburger et al. 2002a) (see also Nishida 1991; Takahashi et al. 2001b; Takahashi and Okada 2002 in support of the sister-group relationship between the Tropheini and haplochromine representatives of lakes Victoria and Malawi). Likewise, a strict geographical circumscription of the Lake Malawi species flock fails, technically, if-as has been suggested based on mitochondrial DNA markers (Moran et al. 1994; Meyer et al. 1996b; Shaw et al. 2000) and AFLP analyses (Seehausen et al. 2003) - the riverine species Astatotilapia calliptera is not the most ancestral taxon of the species flock but nested therein. Molecular phylogenetic and phylogeographic studies have thus revealed that at least some East African lacustrine cichlid adaptive radiations were not restricted to the respective lake habitat.

The second fish species flock criterion of high levels of endemicity (Greenwood 1984a; Mayr 1984) is certainly fulfilled by all species flocks of cichlid fishes in East Africa, as the amount of endemism in the different lakes' cichlid assemblages reaches almost 100\%. Remarkably, the species flocks/assemblages of Lakes Tanganyika, Malawi, and Victoria do not have a single cichlid species in common (Fryer and Iles 1972).

Similarly, the third criterion of close phyletic relationships (Greenwood 1984a; Mayr 1984) is true for the East African cichlid species flocks. Moreover, the two most species-rich species flocks, those of the Lake Malawi region and the Lake Victoria region, have been confirmed to be (almost) monophyletic (see, e.g., Meyer et al. 1990; Shaw et al. 2000; Verheyen et al. 2003). Lake Tanganyika, on the other hand, represents an assemblage of oligophyletic origin (Nishida 1991; Kocher et al. 1995; Salzburger et al. 2002a) and part of its eco-morphological diversity is actually explained by the fact that several more ancient lineages are likely to have radiated in parallel after the formation of the lakes. For example, the substrate-spawning Lamprologini and the Tanganyikan mouthbrooders (Salzburger et al. 2002a), which account for about $90 \%$ of the lakes' cichlid species, have radiated in parallel. As a consequence of its oligophyly, the Lake Tanganyika cichlids should not be considered as a single species flock but rather as several species flocks within a single lake. According to the molecular phylogenies (Nishida 1991; Kocher et al. 1995; Salzburger et al. 2002a), one should consider the Trematocarini (8 species), the Bathybatini (8 species), the Eretmodini (4 species), the Lamprologini ( 100 species), and the Tanganyikan mouthbrooders or even subgroups thereof $(\sim 80$ 
species) as independent or parallel intralacustrine species flocks (see Fig. 3). All these lineages are likely to have seeded the lake independently and to have subsequently radiated in the lacustrine environment (Salzburger et al. 2002a), so that the criterion of a close phyletic relationship (Greenwood 1984a), which we, and others previously (Kosswig 1963; Greenwood 1984a), consider a synonym for monophyly, is not fulfilled. That the Lake Tanganyika species assemblage consists of several species flocks had already been suggested by (Kosswig 1963), who saw in the Lamprologini an independent radiation compared with other cichlids of the lake. The entire cichlid community in Lake Tanganyika should then be referred to as "assemblage" rather than "species flock." Also, for the haplochromines that inhabit Lake Victoria, which are part of the Lake Victoria region superflock (Verheyen et al. 2003), the term "assemblage" would reflect better the fact that the lake's cichlids flock into a higher-level species amalgamation which includes the species of neighboring lakes and rivers as well.

\section{Three areas of uncertainty}

In his 1984 review, Ernst Mayr highlighted three major areas of uncertainty that, by that time, prevented a definitive answer to the question whether sympatric speciation occurs in species flocks of freshwater lakes, and, furthermore, what the relative importance of different allopatric processes in the formation of these flocks was. He noticed uncertainties concerning the age of the species flocks, the taxonomic status of the species, and the cladistic techniques by which the members of the species flocks were analyzed (Mayr 1984).

Advances in the fields of paleogeology and paleolimnology have in the meantime advanced our understanding of the evolution of the East African Rift System and the formation of the lakes (see e.g., Cohen et al. 1993, 1997; Delvaux 1995; Lezzar et al. 1996). Even more important types of data on the "cichlid problem" were recent phylogenetic, phylogeographic, and population-genetic outcomes on the age, the phyletic status (mono- vs. oligophyletic), and the origin of the seeding lineages of the assemblages of the three large lakes as well as other bodies of water in East Africa (Meyer et al. 1990; Kocher et al. 1993. 1995; Salzburger et al. 2002a; Seehausen et al. 2003; Verheyen et al. 2003).

While the timing of the evolutionary processes in East African cichlids is fairly well documented (see above), there are ongoing debates on the taxonomic status of many cichlid species, lineages, and even species flocks (see e.g., Snoeks et al. 1994; Turner et al. 2001; Genner et al. 2004). The taxonomy of the Tanganyikan cichlids is relatively well established (Poll 1986), which is mostly due to the existence of morphological characteristics that distinguish the different tribes and species. Molecular phylogenetic studies largely confirmed the tribal assignments and well-supported phylogenetic hypotheses exist that interrelate the tribes and their respective members (see e.g., Kocher et al. 1995; Takahashi et al. 1998; Salzburger et al. 2002a); and, moreover, it is now possible to infer sister-species relationships by standard molecular techniques (see e.g., Kocher et al. 1995; Salzburger et al. 2002a; Sturmbauer et al. 2003; Koblmüller et al. 2004). Also, unlike in the species flocks of Lake Malawi and the Lake Victoria region (Moran and Kornfield 1993; Verheyen et al. 2003; Salzburger et al. 2004; R.O. Abila et al., unpublished), shared haplotypes between species have not been observed in Tanganyikan lineages (Sturmbauer et al. 2003) except as a result of hybridization (Rüber et al. 2001). Taxonomic uncertainties still remain among closely related taxa in Lake Malawi and, in particular, in the hundreds of closely related species of the Lake Victoria cichlid assemblage. In the latter case, due to the extreme pace of species formation, neither morphological nor molecular data has so far been able to provide sufficient phylogenetic resolution to infer statistically reliable sister-species relationships or hypotheses about the relationships between different genera. It has, however, also been pointed out that the population structure within Lake Victoria cichlids has not been studied extensively (Rico et al. 2003).

That the inference of the phylogeny based on molecular data among closely related cichlid species in Lake Malawi, and particularly in Lake Victoria, remains a challenge has to do to some extent with the type of data and the analyses that have been used so far to address the problem. Additionally, it is still an elusive goal to establish a well-supported phylogeny of the Lake Victoria superflock, since these species are so young and the genetic differences are so slight. Mitochondrial DNA sequences have proved to be reliable markers for the reconstruction of the phylogeny of the major cichlid lineages and older species assemblages (Meyer et al. 1990; Kocher et al. 1995; Shaw et al. 2000; Klett and Meyer 2002; Salzburger et al. 2002a) and the inference of phylogeography in all East African cichlids (here, shared haplotypes between species do not pose a problem) (Sturmbauer and Meyer 1992; Meyer et al. 1996a; Verheyen et al. 1996, 2003; Rüber et al. 2001; Baric et al. 2003; R.O. Abila et al., unpublished). In the cases where the insertion of short interspersed nuclear elements (SINEs) in the nuclear genome has been studied, the prior mitochondrial phylogenies were confirmed (Takahashi et al. 1998, 2001a, 2001b; Takahashi and Okada 2002). But, since SINE insertions are evolutionarily rare events, they may never provide enough phylogenetic resolution to resolve relationships among the more closely related species (flocks). Mitochondrial DNA sequence data also proved useful to investigate the parallel evolution of certain morphological traits between the species assemblages of Lakes Tanganyika and Malawi as well as within the Lake Tanganyika cichlid assemblage (see e.g., Kocher et al. 1993; Rüber et al. 1999; Sturmbauer et al. 2003).

For phylogenetic inference among closely related taxa in the younger assemblages, mitochondrial DNA markers, although evolving five to ten times faster compared with the nuclear genome, are still too slowly evolving, which is 
reflected by shared haplotypes between species (Moran and Kornfield 1993; Verheyen et al. 2003; R.O. Abila et al., unpublished). Recently, Hey et al. (2004) developed a method which uses the information provided by microsatellite repeats and the nuclear haplotypic information provided by flanking region sequences in closely related Lake Malawi mbuna species. Albertson et al. (1999) used a novel approach to overcome the problem of the persistence of ancestral polymorphism in closely related mbuna cichlids of Lake Malawi by analyzing more than a thousand polymorphic markers derived from a DNA fingerprinting method (AFLP). This method has meanwhile been adopted by others (Allender et al. 2003; Seehausen et al. 2003). Allender et al. (2003) was able to show, for example, that in the Lake Malawi mbuna cichlids, similar types of nuptial coloration have evolved repeatedly in several lineages. However, only a few taxa have been studied so far using the AFLP method; also the comparison of results between studies from different laboratories is problematic when using this technique. Nonetheless, approaches using thousands of polymorphic markers that are distributed over the whole genome, such as AFLPs, or the analysis of hundreds of single nucleotide polymorphisms (SNPs), have the potential to considerably advance our understanding of the phyletic relationships within arrays of closely related cichlid species. This type of data might be necessary for the analysis/determination of patterns of relationships as well as studies of the mechanisms of speciation.

\section{Multiple colonization, species flock amalgamation, or intralacustrine speciation?}

Molecular phylogenetic and phylogeographic studies clearly show that multiple colonization from riverine stocks (Mayr 1984) is a negligible factor for species richness, as the most species-rich flocks-those of the Lake Malawi region and the Lake Victoria region-have each been founded by a single lineage of haplochromine ancestors only (Meyer et al. 1990; Kocher et al. 1993; Moran et al. 1994; Nagl et al. 2000; Shaw et al. 2000; Seehausen et al. 2003; Verheyen et al. 2003). For the Lake Tanganyika cichlids (Nishida 1991; Kocher et al. 1995; Salzburger et al. 2002a), several independent species flocks derived from a small number of seeding lineages make up the assemblage (see above), and several lineages have left the lake secondarily (Sturmbauer et al. 1994; Salzburger et al. 2002a). However, the ages of the parallel intralacustrine species flocks of Lake Tanganyika, where all radiations have occurred after the formation of the lakes (Sturmbauer et al. 1994; Salzburger et al. 2002a), suggest that the diversity within Lake Tanganyika's parallel species flocks was almost entirely shaped via intralacustrine speciation.

The Lake Victoria superflock might be viewed as an amalgamation of independent species flocks in Lakes Victoria, Albert, Edward, George, Kyoga, and Kivu-all were founded by the same lineage of haplochromine an- cestors. Moreover, the 500 or so species of the main lake (Lake Victoria) were recently suggested to be diphyletic (Verheyen et al. 2003), which seems to implicate that the amalgamation of several independent species flocks could explain the unique species richness in that lake or in the whole superflock. However, the second seeding lineage of Lake Victoria cichlids is represented by one rock-dwelling species so far, so that the second lineage combines some 500 species that most likely have arisen in the lake basin within the last $\sim 100,000$ years (Fryer 1997, 2001, 2004; Nagl et al. 2000; Verheyen et al. 2003). Molecular data thus agree in affirming that intralacustrine speciation is the dominant mode of species multiplication in all East African lake cichlid species flocks (Meyer et al. 1990; Kocher et al. 1993; Meyer 1993; Stiassny and Meyer 1999; Salzburger et al. 2002a).

\section{Allopatric intralacustrine speciation}

The term "intralacustrine speciation" connotes not much more than that the speciation events took place within the confines of the respective lakes, and that neither multiple colonization nor amalgamation of independent species flocks is responsible for the observed species richness. Importantly, intralacustrine speciation does not specify which mechanism(s) of speciation was/were involved. Mayr (1984) mentioned three possibilities through which allopatric intralacustrine speciation might take place.

1. Major lake level fluctuations may be factors that "would permit some extent of allopatric speciation within the lake" (Mayr 1984). Large lake level changes caused by variations in rainfall, evaporation, and/or tectonic activities are known in all East African lakes (Beadle 1974; Scholz and Rosendahl 1988; Cohen et al. 1993, 1997; Delvaux 1995; Johnson et al. 1996; Lezzar et al. 1996; Nicholson 1999). Such fluctuations have been interpreted as important external modulators promoting speciation within arrays of closely related species in all the African lakes (Rossiter 1995; Rüber et al. 1998; Sturmbauer 1998; Kornfield and Smith 2000; Sturmbauer et al. 2001), and several studies support the view that lake level fluctuations may influence the genetic divergence in East African lake cichlids and promote allopatric speciation (Owen et al. 1990; Rüber et al. 1998; Danley et al. 2000; Sturmbauer et al. 2001, 2003; Baric et al. 2003).

Allopatric speciation would, according to Mayr (1984), also be possible if a lake basin is not divided into sub-basins. He argued that the spotty distribution of many cichlid species would favor intralacustrine allopatric speciation and pointed out that almost none of the cichlid species in East Africa's Great Lakes have a lake-wide distribution and that they occur typically only in an, often small, portion of a lake. Here, phylogeography, i.e., the combination of biogeography and phylogenetics/population-genetic data (Avise et al. 1987), recently offered the opportunity to 
not only map the geographic distribution of morphologically recognized taxa, but also to investigate the biogeography of genetic lineages along the shoreline of a lake. In Tanganyikan rock-dwelling cichlids, for example, mitochondrial lineages tend to have restricted distribution patterns and only a few lineages have a lake wide-distribution (Meyer et al. 1996a; Verheyen et al. 1996; Sturmbauer et al. 1997; Rüber et al. 1998, 2001; Taylor et al. 2001; Baric et al. 2003), which is in agreement with Mayr's (1984) notion. Species of the Lake Malawi mbuna group seem to have even more fine-grained ranges compared with Tanganyikan rock-dwellers (Konings 1990); both assemblages are known for their sometimes extreme philopatry (see, e.g., van Oppen et al. 1997; Arnegard et al. 1999; Rüber et al. 2001; Rico and Turner 2002).

2. Mayr (1984) emphasized the importance of the patchy habitat distribution, due to the alternation of rocky, sandy, and muddy habitats in the Great Lakes, for allopatric intralacustrine speciation. That the island-like properties of these habitats combined with the cichlid's specialization to particular habitat types are an important factor for intralacustrine speciation had already been suggested (Brooks 1950; Mayr 1963; Fryer and Iles 1972); the patchy distribution of many littoral cichlid species, and in particular rock-dwelling ones, in the East African Great Lakes lends obvious support to this hypothesis. Also, the observation that the sizebut not the age, as has also been suggested by Mayr (1942) — of a lake is positively correlated with the species number of a lake's cichlid assemblage (Fig. 4), indicates that the many more ecological opportunities and/or the higher potential for spatial separation a larger lake provides might be an important promoter for micro-allopatric intralacustrine speciation (see also Barluenga and Meyer 2004).

Molecular ecological work has indeed confirmed the importance of substrate discontinuities or deep-water habitats as barriers to gene-flow. Studies on Lake Malawi mbuna cichlids (Reinthal and Meyer 1997; van Oppen et al. 1997; Arnegard et al. 1999; Markert et al. 1999; Danley et al. 2000; Rico and Turner 2002) showed that populations are sometimes extremely small and that sister-species are separated by often only few hundred meters of shoreline. On the other hand, population structuring has not been observed in pelagic cichlids from Lake Malawi, and it has been suggested that these might form lake-wide panmictic populations (Shaw et al. 2000). Demersal cichlid species in Lake Malawi, which are probably as speciesrich as the rock-dwelling mbuna, also seem to display low levels of population structuring (Taylor and Verheyen 2001).

3. Mayr (1984) also argues that the isolation of spawning sites would be an important promoter for allopatric intralacustrine speciation. In Mayr's view, "the isolating mechanisms are acquired during spatial isolation as a byproduct of the genetic changes of the isolated population" (Mayr 1984). He disagrees with Dob-

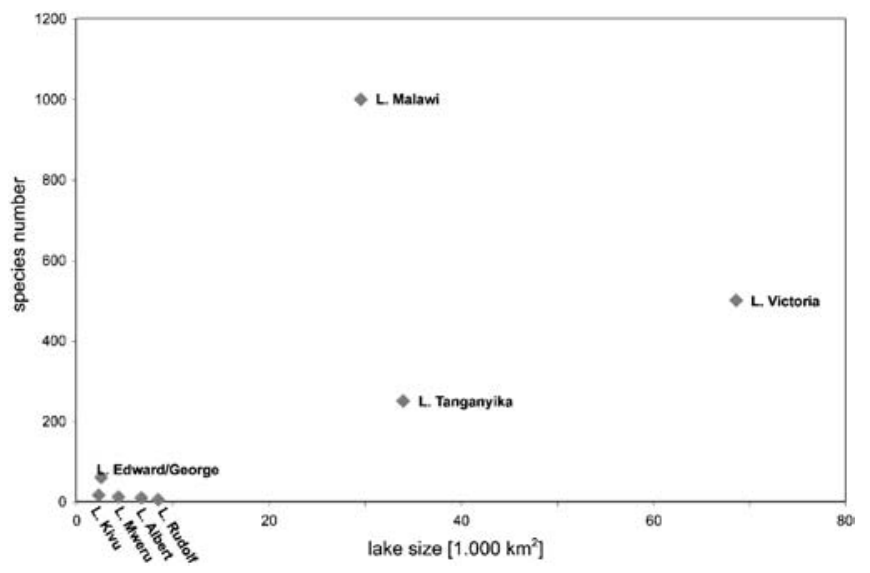

Fig. 4 The size, but not the age, of a lake roughly correlates with its species number of endemic cichlids (Mayr 1942), suggesting that the much higher number of ecological niches and/or the higher potential of spatial separation due to large discontinuous shoreline that are provided by large lake habitats facilitate intralacustrine allopatric speciation (see also Barluenga and Meyer 2004). Lake Malawi is somewhat of an exception, since it has about four times more species than the similarly sized Lake Tanganyika. This canto some extent — be explained by a different taxonomic treatment of its taxa. However, it is likely that the adaptive radiation in Lake Malawi is at a different stage than that of Lake Tanganyika, and that the Lake Tanganyika species assemblage had been more species-rich at some point in the past

zhansky's (1937) concept of hybrid inferiority causing the perfection of isolating mechanisms in secondary sympatry and attests that the almost complete absence of hybrids in the cichlid assemblages of the East African lakes would support his view.

Mayr's and Dobzhansky's views have both been used to explain the evolution of isolating mechanisms in East African lake cichlids (see, e.g., Fryer and Iles 1972; Deutsch 1997; Seehausen and van Alphen 1999; Kornfield and Smith 2000). However, the extreme pace of species formation in the East African cichlids poses difficulties in determining which mode-isolating mechanisms were acquired and possibly perfected secondarily. In addition, the role that hybridization might play in the evolution of cichlid species flocks is disputed [the supposed absence of hybridization was used as argument by Mayr (1984)]. Hybridization has been observed in conditions of reduced water clarity (Seehausen et al. 1997) or after translocation of fishes (Stauffer and Bowers 1996). Recent molecular studies have also revealed that hybridization events did occur between distinct species (Rüber et al. 2001; Salzburger et al. 2002a; Smith et al. 2003). However, the frequency of the occurrence of hybridization events in cichlids has not been studied in sufficient detail to allow statements as to whether hybridization is rare and exceptional or rather common in the cichlid species assemblages. 


\section{Ecological factors vs. sexual selection}

Ernst Mayr (1984) stated that "the probable causal factors in the origin of isolating mechanisms has recently been discovered in sexual selection" and refers to Dominey (1984) in the same compendium, who was the first to discuss the Fisherian runaway sexual selection model with respect to cichlid fishes. Sexual selection via female choice of male (nuptial) coloration is now regarded as important factor in cichlid evolution (see, e.g., Meyer 1993; Turner and Burrows 1995; Deutsch 1997; Seehausen and van Alphen 1999; Kornfield and Smith 2000; Allender et al. 2003). Assortative mating was also seen as a possible mechanism by which sympatric speciation might occur (Turner and Burrows 1995; Seehausen and van Alphen 1999; Wilson et al. 2000; Schliewen et al. 2001; Allender et al. 2003; Barluenga and Meyer 2004), particularly after simulations predicted that sympatric speciation is the theoretical outcome of such set-ups (Dieckmann and Doebeli 1999; Higashi et al. 1999; Kondrashov and Kondrashov 1999; Gavrilets and Waxman 2002).

Mayr (1984), on the other hand, argued that sexual selection would act in small populations, i.e., spatially isolated "mating clusters," and he designated the process as "micro-allopatric." In his view, the first characters of species to diverge would be related to courtship, e.g., behavioral and/or colorational traits. Trophic traits related to ecological differences in the food uptake would be diverging secondarily, in particular, once sympatry was re-established as a form of character displacement after secondary contact (Mayr 1984). Empirical observations show that sibling cichlid species tend to differ in coloration rather than in trophic differences, lending support to this hypothesis (Deutsch 1997; Reinthal and Meyer 1997; Seehausen and van Alphen 1999). Recent molecular studies on sympatric speciation in a trophically and colorationally polymorphic Nicaraguan crater lake cichlid species (Wilson et al. 2000; Barluenga and Meyer 2004) also revealed more pronounced differences between color but not pharyngeal jaw morphologies (a trait related to trophic differences; see Meyer 1989, 1990a, 1990b). Mayr himself considers cichlid examples (e.g. Mayr 2001; $\mathrm{p}$ 100), as the most convincing examples for sympatric speciation (E. Mayr, personal communication)

If, however, cichlid assemblages of entire lake habitats are considered, it seems more likely that, initially, ecological factors lead to a spatial separation into more benthic and more limnetic lineages (Danley and Kocher 2001). Danley and Kocher (2001) presented a three-stage model for the evolution of the cichlid species in Lake Malawi, in which the first stage is characterized by the creation of the macrohabitat clades (see also Streelman et al. 2003b). The second stage would be the trophic specialization within lineages associated with changes in the trophic morphology (Liem 1973, 1980), whereas the third stage, that would lead to the most substantial cycles of species multiplication, would be related to reproductive characters, and particularly to coloration (Danley and Kocher 2001; Streelman and Danley 2003).

The situation in Lake Tanganyika is somewhat similar, in that more ancient lineages tend to occupy marginal or deep-water habitats (Salzburger et al. 2002a); these lineages are also relatively species-poor (Poll 1986). Also, the tribes that are combined in the Tanganyikan mouthbrooders seem to first of all display a specialization to particular habitat types in the lake (Salzburger et al. 2002a), which may be secondarily reversed (Koblmüller et al. 2004). Within these tribes, the more recent radiation and speciation processes seem to be as well related to trophic morphologies (see, e.g., Sturmbauer et al. 2003), whereas colorational differences are found within arrays of closely related species, for instance of the Cyprichromini and the Tropheini. Unlike in Lake Malawi, however, in Lake Tanganyika the different colored morphs are usually not considered as separate species (Poll 1986; Snoeks et al. 1994; Genner et al. 2004).

Clearly, despite the relatively great age of the family Cichlidae, it is not the old lineages that are now represented with large species numbers, but the astonishingly diverse lineages are typically the relatively young ones (see Meyer et al. 1990, 1994; Verheyen et al. 2003). The old lineages also tend to live in open-water and deepwater areas of the lakes. It is therefore possible that the older species flocks of cichlids (in particular that of Lake Tanganyika) had been more species-rich initially, and were "pruned" of species later during their evolution (Meyer 1993; Schluter 2000; Salzburger et al. 2002a; Streelman and Danley 2003). To test this assumption one would need to find out whether older lineages, compared with younger ones, are characterized by being speciespoor due to extinction events. There are comparative method approaches (Nee et al. 1994; Harvey and Rambaut 2000; Pybus and Harvey 2000) that use molecular phylogenies with which these might be testable. However, without a fossil record, it may remain difficult to know whether those ancient lineages used to be more speciesrich (and possibly colorful) and how many species became extinct (possibly due to competitive extinction by more competitive younger lineages) or whether those rather ancient lineages were never particularly successful in terms of the formation of new species.

\section{Conclusions and outlook}

Twenty years ago, Ernst Mayr stated that the extraordinary evolutionary success of cichlids might require special explanations. "It is thus evident that there must be some aspect in the life history and perhaps the genome of certain taxa which permit them to speciate rapidly inside of lakes" (Mayr 1984). In this age of genomics, the types of molecular data that are being collected on the "cichlid problem" are becoming increasingly sophisticated and promise to yield entirely new insights that might one day, sooner rather than later, answer the question as to whether there are some special molecular evolutionary mecha- 
nisms acting in the genome of cichlids that might be at least partly responsible for their evolutionary success compared with that of other families of fishes that also live in East African lakes. Several types of genomic resources such as genetic maps, cDNA and BAC libraries, and cDNA-microarrays have been established and there is currently an effort underway to have a genome of a cichlid fish determined (Kocher et al. 2004; Kocher 2004). In addition, approaches such as QTL (quantitative trait loci) studies (Albertson et al. 2003; Streelman et al. 2003a) have been employed and more work is in progress using this novel method. This entirely new approach, which was still quite inconceivable 20 years ago, promises to unveil some of the secrets of the cichlids that they still hold as a model system for exuberant biological diversification and explosive speciation.

Acknowledgements We wish to dedicate this article to Ernst Mayr, in great admiration and friendship and with our best wishes for his 100 th birthday. We are grateful to $M$. Barluenga and the reviewers for valuable comments. We would also like to acknowledge the financial support of the Deutsche Forschungsgemeinschaft, the Landesstiftung Baden-Württemberg, and the Center for Junior Research Fellows at the University of Konstanz.

\section{References}

Albertson RC, Markert JA, Danley PD, Kocher TD (1999) Phylogeny of a rapidly evolving clade: the cichlid fishes of Lake Malawi, East Africa. Proc Natl Acad Sci USA 96:5107-5110

Albertson RC, Streelman JT, Kocher TD (2003) Directional selection has shaped the oral jaws of Lake Malawi cichlid fishes. Proc Natl Acad Sci USA 100:5252-5257

Allender CJ, Seehausen O, Knight ME, Turner GF, Maclean N (2003) Divergent selection during speciation of Lake Malawi cichlid fishes inferred from parallel radiations in nuptial coloration. Proc Natl Acad Sci USA 100:14074-14079

Arnegard ME, Markert JA, Danley PD, Stauffer JR, Ambali AJ, Kocher TD (1999) Population structure and colour variation of the cichlid fish Labeotropheus fuelleborni Ahl along a recently formed archipelago of rocky habitat patches in southern Lake Malawi. Proc R Soc Lond B Biol Sci 266:119-130

Avise JC, Arnold J, Ball RM, Bermingham E, Lamb T, Neigel JE, Reeb CA, Saunders NC (1987) Intraspecific phylogeography: the mitochondrial DNA bridge between population genetics and systematics. Annu Rev Ecol Evol Syst 18:459-522

Baric S, Salzburger W, Sturmbauer C (2003) Phylogeography and evolution of the Tanganyikan cichlid genus Tropheus based upon mitochondrial DNA sequences. J Mol Evol 56:54-68

Barlow GW (2000) The cichlid fishes: Nature's grand experiment in evolution. Perseus, Cambridge, Mass.

Barluenga M, Meyer A (2004) The Midas cichlid species complex: incipient sympatric speciation in Nicaraguan crater lake cichlid fishes. Mol Ecol 13

Beadle L (1974) The Inland waters of tropical Africa. Longman, London

Booton GC, Kaufman L, Chandler M, Oguto-Ohwayo R, Duan W, Fuerst PA (1999) Evolution of the ribosomal RNA internal transcribed spacer one (ITS-1) in cichlid fishes of the Lake Victoria region. Mol Phylogenet Evol 11:273-282

Boulenger G (1898) Catalogue of the fresh-water fishes of Africa in the British Museum (Natural History). British Museum for Natural History, London

Brooks JL (1950) Speciation in ancient lakes. Q Rev Biol 25:30176
Cohen AS, Soreghan M, Scholz CA (1993) Estimating the age of formation of lakes: an example from Lake Tanganyika, East African Rift system. Geology 21:511-514

Cohen AS, Lezzar KE, Tiercelin JJ, Soreghan M (1997) New paleogeographic and lake-level reconstructions of Lake Tanganyika: implications for tectonic, climatic and biological evolution in a rift lake. Basin Res 7:107-132

Coulter GW (1991) Lake Tanganyika and its life. Oxford University Press, Oxford

Danley PD, Kocher TD (2001) Speciation in rapidly diverging systems: lessons from Lake Malawi. Mol Ecol 10:1075-1086

Danley PD, Markert JA, Arnegard ME, Kocher TD (2000) Divergence with gene flow in the rock-dwelling cichlids of Lake Malawi. Evolution 54:1725-1737

Delvaux D (1995) Age of Lake Malawi (Nyasa) and water level fluctuations. Mus R Afr Centr Tervuren (Belg.) Dept Geol Min Rapp Ann 1995-1996:99-108

Deutsch JC (1997) Colour diversification in Malawi cichlids: evidence for adaptation, reinforcement or sexual selection? Biol J Linn Soc 62:1-14

Dieckmann U, Doebeli M (1999) On the origin of species by sympatric speciation. Nature 400:354-357

Dobzhansky T (1937) Genetics and the origin of species. Columbia University Press, New York

Dominey WJ (1984) Effects of sexual selection and life history on speciation: species flocks in African cichlids and Hawaiian Drosophila. In: Echelle AA, Kornfield I (eds) Evolution of fish species flocks. University of Maine at Orono Press, Orono, Me., pp 231-250

Echelle AA, Kornfield I (1984) Evolution of fish species flocks. University of Maine at Orono Press, Orono, Me.

Farias IP, Orti G, Meyer A (2000) Total evidence: molecules, morphology, and the phylogenetics of cichlid fishes. J Exp Zool 288:76-92

Farias IP, Orti G, Sampaio I, Schneider H, Meyer A (2001) The cytochrome $b$ gene as a phylogenetic marker: the limits of resolution for analyzing relationships among cichlid fishes. J Mol Evol 53:89-103

Fryer G (1997) Biological implications of a suggested Late Pleistocene desiccation of Lake Victoria. Hydrobiologia 354:177182

Fryer G (2001) On the age and origin of the species flock of haplochromine cichlid fishes of Lake Victoria. Proc R Soc Lond B Biol Sci 268:1147-1152

Fryer G (2004) Speciation rates in lakes and the enigma of Lake Victoria. Hydrobiologia 515

Fryer G, Iles TD (1972) The cichlid fishes of the Great Lakes of Africa: their biology and evolution. Oliver and Boyd, Edinburgh

Gavrilets S, Waxman D (2002) Sympatric speciation by sexual conflict. Proc Natl Acad Sci USA 99:10533-10538

Genner MJ, Seehausen O, Cleary DFR, Knight ME, Michel E, Turner GF (2004) How does the taxonomic status of allopatric populations influence species richness within African cichlid fish assemblages? J Biogeogr 31:93-102

Goodwin NB, Balshine-Earn S, Reynolds JD (1998) Evolutionary transitions in parental care in cichlid fish. Proc R Soc Lond B Biol Sci 265:2265-2272

Greenwood PH (1973) Morphology, endemism and speciation in African cichlid fishes. Verh Dtsch Zool Ges 66:115-124

Greenwood PH (1979) Towards a phyletic classification of the 'genus' Haplochromis (Pisces, Cichlidae) and related taxa. Bull Br Mus Nat Hist Zool 35:265-322

Greenwood PH (1980) Towards a phyletic classification of the 'genus' Haplochromis (Pisces, Cichlidae) and related taxa. Part 2. Bull Br Mus Nat Hist Zool 39:1-99

Greenwood PH (1984a) What is a species flock. In: Echelle AA, Kornfield I (eds) Evolution of fish species flocks. University of Maine at Orono Press, Orono, Me., pp 13-20

Greenwood PH (1984b) African cichlids and evolutionary theories. In: Echelle AA, Kornfield I (eds) Evolution of fish species 
flocks. University of Maine at Orono Press, Orono, Me., pp 141-155

Harvey PH, Rambaut A (2000) Comparative analyses for adaptive radiations. Philos Trans R Soc Lond B Biol Sci 355:1599-1605

Hey J, Won Y-J, Sivasundar A, Nielsen R, Markert JA (2004) Using nuclear haplotypes with microsatellites to study gene flow between recently separated cichlid species. Mol Ecol 13, 909-919

Higashi M, Takimoto G, Yamamura N (1999) Sympatric speciation by sexual selection. Nature 402:523-526

Johnson TC, Ng'ang'a P (1990) Reflections on a rift lake. In: Katz BJ (ed) Lacustrine basin exploration: case studies and modern analogs. American Association of Petroleum Geologists Memoir, pp 113-135

Johnson TC, Scholz CA, Talbot MR, Kelts K, Ricketts RD, Ngobi G, Beuning K, Ssemmanda II, McGill JW (1996) Late Pleistocene desiccation of Lake Victoria and rapid evolution of cichlid fishes. Science 273:1091-1093

Klett V, Meyer A (2002) What, if anything, is a tilapia? Mitochondrial ND2 phylogeny of tilapiines and the evolution of parental care systems in the African cichlid fishes. Mol Biol Evol 19:865-883

Knight ME, Turner GF, Rico C, Oppen MJ van, Hewitt GM (1998) Microsatellite paternity analysis on captive Lake Malawi cichlids supports reproductive isolation by direct mate choice. Mol Ecol 7:1605-1610

Koblmüller S, Salzburger W, Sturmbauer C (2004) Evolutionary relationships in the sand-dwelling cichlid lineage of lake Tanganyika suggest multiple colonization of rocky habitats and convergent origin of biparental mouthbrooding. J Mol Evol 58:79-96

Kocher TD (2004) Adaptive evolution and explosive speciation: the cichlid fish model. Nature Rev Genet 5:288-298

Kocher TD, Conroy JA, McKaye KR, Stauffer JR (1993) Similar morphologies of cichlid fish in lakes Tanganyika and Malawi are due to convergence. Mol Phylogenet Evol 2:158-165

Kocher TD, Conroy JA, McKaye KR, Stauffer JR, Lockwood SF (1995) Evolution of NADH dehydrogenase subunit 2 in East African cichlid fish. Mol Phylogenet Evol 4:420-432

Kocher TD, Fernald R, Hofmann H, Meyer A, Okada N, Penman DJ, Seehausen O (2004) Genome sequence of a cichlid fish: the Nile tilapia (Oreochromis niloticus). Proposal submitted to the JGI Community Sequencing Program by the Cichlid Genome Consortium: see http://www.hcgs.unh.edu/cichlid/

Kondrashov AS, Kondrashov FA (1999) Interactions among quantitative traits in the course of sympatric speciation. Nature 400:351-354

Konings A (1990) Cichlids and all other fishes of Lake Malawi. THF, Neptune, N.J.

Kornfield I, Smith PF (2000) African cichlid fishes: model systems for evolutionary biology. Annu Rev Ecol Syst 31:163-196

Kosswig C (1947) Selective mating as a factor speciation in cichlid fish of East African lakes. Nature 159:604

Kosswig C (1963) Ways of speciation in cichlids. Copeia 1963: $238-244$

Lezzar KE, Tiercelin JJ, De Batist M, Cohen AS, Bandora T, Van Regensbergen P, Le Turdu C, Mifundu W, Klerkx J (1996) New seismic stratigraphy and Late Tertiary history of the North Tanganyika Basin, East African Rift system, deduced from multichannel and high-resolution reflection seismic data and piston core evidence. Basin Res 8:1-28

Liem KF (1973) Evolutionary strategies and morphological innovations: cichlid pharyngeal jaws. Syst Zool 22:425-441

Liem KF (1980) Adaptive significance of intra- and interspecific differences in the feeding repertoires of cichlid fishes. Am Zool 20:295-314

Markert JA, Arnegard ME, Danley PD, Kocher TD (1999) Biogeography and population genetics of the Lake Malawi cichlid Melanochromis auratus: habitat transience, philopatry and speciation. Mol Ecol 8:1013-1026

Mayr E (1942) Systematics and the origin of species. Columbia University Press, New York
Mayr E (1947) Ecological factors in speciation. Evolution 1:263288

Mayr E (1963) Animal species and evolution. Harvard University Press, Cambridge, Mass.

Mayr E (1984) Evolution of fish species flocks: a commentary. In: Echelle AA, Kornfield I (eds) Evolution of fish species flocks. University of Maine at Orono Press, Orono, Me., pp 3-12

Mayr E (2001) What evolution is. Basic books, New York

Mayr E, Brock WJ (2002) Classifications and other ordering systems. J Zool Syst Evol Res 40:169-194

Meyer A (1989) Costs and benefits of morphological specialization: feeding performance in the trophically polymorphic Neotropical cichlid fish, Cichlasoma citrinellum. Oecologia 80:431-136

Meyer A (1990a) Ecological and evolutionary aspects of the trophic polymorphism in Cichlasoma citrinellum (Pisces: Cichlidae). Biol J Linn Soc 39:279-299

Meyer A (1990b) Morphometrics and allometry of the trophically polymorphic cichlid fish, Cichlasoma citrinellum: alternative adaptations and ontogenetic changes in shape. J Zool 221:237260

Meyer A (1993) Phylogenetic relationships and evolutionary processes in East African cichlids. Trends Ecol Evol 8:279-284

Meyer A, Kocher TD, Basasibwaki P, Wilson AC (1990) Monophyletic origin of Lake Victoria cichlid fishes suggested by mitochondrial DNA sequences. Nature 347:550-553

Meyer A, Montero C, Spreinat A (1994) Evolutionary history of the cichlid fish species flocks of the East African great lakes inferred from molecular phylogenetic data. Adv Limnol 44:409425

Meyer A, Knowles LL, Verheyen E (1996a) Widespread geographical distribution of mitochondrial haplotypes in rockdwelling cichlid fishes from Lake Tanganyika. Mol Ecol $5: 341-350$

Meyer A, Montero CM, Spreinat A (1996b) Molecular phylogenetic inferences about the evolutionary history of the East African cichlid fish radiations. In: Johnson TC, Odada EO (eds) Limnology, climatology and paleoclimatology of the East African lakes. Gordon and Breach Scientific, Toronto, pp 303323

Moran P, Kornfield I (1993) Retention of an ancestral polymorphism in the Mbuna species flock (Teleostei: Cichlidae) of Lake Malawi. Mol Biol Evol 10:1015-1029

Moran P, Kornfield I, Reinhal PN (1994) Molecular systematics and radiation of the haplochromine cichlids (Teleostei: Perciformes) of Lake Malawi. Copeia 2:274-288

Nagl S, Tichy H, Mayer WE, Takahata N, Klein J (1998) Persistence of neutral polymorphisms in Lake Victoria cichlid fish. Proc Natl Acad Sci USA 95:14238-14243

Nagl S, Tichy H, Mayer WE, Takezaki N, Takahata N, Klein J (2000) The origin and age of haplochromine fishes in Lake Victoria, East Africa. Proc R Soc Lond B Biol Sci 267:1049_ 1061

Nee S, Holmes EC, May RM, Harvey PH (1994) Extinction rates can be estimated from molecular phylogenies. Philos Trans R Soc Lond B Biol Sci 344:77-82

Nicholson SE (1999) Historical and modern fluctuations of Lakes Tanganyika and Rukwa and their relationships to rainfall variability. Climatic Change 41:53-71

Nishida M (1991) Lake Tanganyika as an evolutionary reservoir of old lineages of East African cichlid fishes: inferences from allozyme data. Experientia 47:974-979

Oppen MJ van, Turner GF, Rico C, Deutsch JC, Ibrahim KM, Robinson RL, Hewitt GM (1997) Unusually fine-scale genetic structuring found in rapidly speciating Malawi cichlid fishes. Proc R Soc Lond B Biol Sci 264:1803-1812

Oppen MJ van, Turner GF, Rico C, Robinson RL, Deutsch JC, Genner MJ, Hewitt GM (1998) Assortative mating among rockdwelling cichlid fishes supports high estimates of species richness from Lake Malawi. Mol Ecol 7:991-1001

Owen RB, Crossley R, Johnson TC, Tweddle D, Kornfield I, Davison S, Eccles DH, Engstrom DE (1990) Major low levels 
of Lake Malawi and implications for evolution rates in cichlid fishes. Proc R Soc Lond B Biol Sci 240:519-553

Poll M (1986) Classification des Cichlidae du lac Tanganika: tribus, genres et espèces. Memoires de la classe des sciences. T. XLV. Fascicule 2 edn. Académie Royale de Belgique, Brussels

Pybus OG, Harvey PH (2000) Testing macro-evolutionary models using incomplete molecular phylogenies. Proc R Soc Lond B Biol Sci 267:2267-2272

Reinthal PN, Meyer A (1997) Molecular phylogenetic tests of speciation models in Lake Malawi cichlid fishes. In: Givinish TJ, Sytsma KJ (eds) Evolution and adaptive radiations. Cambridge University Press, Cambridge, pp 189-224

Rensch B (1933) Zoologsiche Systematik und Artbildungsproblem. Verh Dtsch Zool Ges 1933:19-83

Rico C, Turner GF (2002) Extreme microallopatric divergence in a cichlid species from Lake Malawi. Mol Ecol 11:1585-1590

Rico C, Bouteillon P, Oppen MJ van, Knight ME, Hewitt GM, Turner GF (2003) No evidence for parallel sympatric speciation in cichlid species of the genus Pseudotropheus from northwestern Lake Malawi. J Evol Biol 16:37-46

Rossiter A (1995) The cichlid fish assemblages of Lake Tanganyika: ecology, behavior and evolution of its species flocks. Adv Ecol Res 26:157-252

Rüber L, Verheyen E, Sturmbauer C, Meyer A (1998) Lake level fluctuations and speciation in rock-dwelling cichlid fish in Lake Tanganyika, East Africa. In: Grant PR (ed) Evolution on islands. Oxford University Press, New York, pp 225-240

Rüber L, Verheyen E, Meyer A (1999) Replicated evolution of trophic specializations in an endemic cichlid fish lineage from Lake Tanganyika. Proc Natl Acad Sci USA 96:10230-10235

Rüber L, Meyer A, Sturmbauer C, Verheyen E (2001) Population structure in two sympatric species of the Lake Tanganyika cichlid tribe Eretmodini: evidence for introgression. Mol Ecol 10:1207-1225

Sage RD, Loiselle PV, Basasibwaki P, Wilson AC (1984) Molecular versus morphological change among cichlid fishes of Lake Victoria. In: Echelle AA, Kornfield I (eds) Evolution of fish species flocks. University of Maine at Orono Press, Orono, Me., pp 185-202

Salzburger W, Meyer A, Baric S, Verheyen E, Sturmbauer C (2002a) Phylogeny of the Lake Tanganyika cichlid species flock and its relationship to the Central and East African haplochromine cichlid fish faunas. Syst Biol 51:113-135

Salzburger W, Baric S, Sturmbauer C (2002b) Speciation via introgressive hybridization in East African cichlids? Mol Ecol 11:619-625

Salzburger W, Verheyen E, Snoeks J, Meyer A (2004) Response to technical comment. Science (in press)

Schliewen UK, Tautz D, Paabo S (1994) Sympatric speciation suggested by monophyly of crater lake cichlids. Nature 368:629-632

Schliewen U, Rassmann K, Markmann M, Markert J, Kocher T, Tautz D (2001) Genetic and ecological divergence of a monophyletic cichlid species pair under fully sympatric conditions in Lake Ejagham, Cameroon. Mol Ecol 10:1471-1488

Schluter D (2000) The ecology of adaptive radiation. Oxford University Press, New York

Scholz CA, Rosendahl BR (1988) Low lake stands in Lakes Malawi and Tanganyika, East Africa, delineated with multifold seismic data. Science 240:1645-1648

Seehausen O (1996) Lake Victoria rock cichlids: taxonomy, ecology, and distribution. Verdujin Cichlids, Zevenhuizen, The Netherlands

Seehausen O (2002) Patterns in fish radiation are compatible with Pleistocene desiccation of Lake Victoria and 14,600-year history for its cichlid species flock. Proc R Soc Lond B Biol Sci 269:491-470

Seehausen O, Alphen JJM van (1999) Can sympatric speciation by disruptive sexual selection explain rapid evolution of cichlids diversity in Lake Victoria? Ecol Lett 2:262-271
Seehausen O, Alphen JJM van, Witte F (1997) Cichlid fish diversity threatened by eutrophication that curbs sexual selection. Science 277:1808-1811

Seehausen O, Alphen JJM van, Lande R (1999) Color polymorphism and sex ratio distortion in a cichlid fish as an incipient stage in sympatric speciation by sexual selection. Ecol Lett $2: 367-378$

Seehausen O, Koetsier E, Schneider MV, Chapman LJ, Chapman CA, Knight ME, Turner GF, Alphen JJM van, Bills R (2003) Nuclear markers reveal unexpected genetic variation and a Congolese-Nilotic origin of the Lake Victoria cichlid species flock. Proc R Soc Lond B Biol Sci 270:129-137

Shaw PW, Turner GF, Idid MR, Robinson RL, Carvalho GR (2000) Genetic population structure indicates sympatric speciation of Lake Malawi pelagic cichlids. Proc R Soc Lond B Biol Sci 267:2273-2280

Smith PF, Konings A, Kornfield I (2003) Hybrid origin of a cichlid population in Lake Malawi: implications for genetic variation and species diversity. Mol Ecol 12:2497-2504

Snoeks J, Rüber L, Verheyen E (1994) The Tanganyika problem: comments on the taxonomy and distribution patterns of its cichlid fauna. In: Martens K, Goddeeris G, Coulter GW (eds) Speciation in ancient lakes. Schweizerbart'sche Verlagsdruckerei, Stuttgart, pp 355-372

Sparks JS (2004) Molecular phylogeny and biogeography of the Malagasy and South Asian cichlids (Teleostei: Perciformes: Cichlidae). Mol Phylogenet Evol 30:599-614

Stauffer JR, Bowers NJ (1996) Evidence of hybridization between Cynotilapia afra and Pseudotropheus zebra (Teleostei: Cichlidae) following an intralacustrine translocation in Lake Malawi. Copeia 1996:203-208

Stiassny MLJ, Meyer A (1999) Cichlids of the Rift Lakes. Sci Am 280(2):64-69

Streelman JT, Danley PD (2003) The stages of vertebrate evolutionary radiation. Trends Ecol Evol 18:126-131

Streelman JT, Zardoya R, Meyer A, Karl SA (1998) Multilocus phylogeny of cichlid fishes (Pisces: Perciformes): evolutionary comparison of microsatellite and single-copy nuclear loci. Mol Biol Evol 15:798-808

Streelman JT, Albertson RC, Kocher TD (2003a) Genome mapping of the orange blotch colour pattern in cichlid fishes. Mol Ecol 12:2465-2471

Streelman JT, Webb JF, Albertson RC, Kocher TD (2003b) The cusp of evolution and development: a model of cichlid tooth shape diversity. Evol Dev 5:600-608

Sturmbauer C (1998) Explosive speciation in cichlid fishes of the African Great Lakes: a dynamic model of adaptive radiation. J Fish Biol 53 (Suppl A):18-36

Sturmbauer C, Meyer A (1992) Genetic divergence, speciation and morphological stasis in a lineage of African cichlid fishes. Nature 358:578-581

Sturmbauer C, Verheyen E, Meyer A (1994) Mitochondrial phylogeny of the Lamprologini, the major substrate spawning lineage of cichlid fishes from Lake Tanganyika in Eastern Africa. Mol Biol Evol 11:691-703

Sturmbauer C, Rüber L, Verheyen E, Meyer A (1997) Phylogeographic patterns in populations of cichlid fishes from rocky habitats in Lake Tanganyika. In: Kocher TD, Stepien C (eds) Molecular systematics of fishes. Academic Press, New York, pp 93-107

Sturmbauer C, Baric S, Salzburger W, Rüber L, Verheyen E (2001) Lake level fluctuations synchronize genetic divergences of cichlid fishes in African lakes. Mol Biol Evol 18:144-154

Sturmbauer C, Hainz U, Baric S, Verheyen E, Salzburger W (2003) Evolution of the tribe Tropheini from Lake Tanganyika: synchronized explosive speciation producing multiple evolutionary parallelism. Hydrobiologia 500:51-64

Takahashi K, Okada N (2002) Mosaic structure and retropositional dynamics during evolution of subfamilies of short interspersed elements in African cichlids. Mol Biol Evol 19:1303-1312

Takahashi K, Terai Y, Nishida M, Okada N (1998) A novel family of short interspersed repetitive elements (SINEs) from cichlids: 
the patterns of insertion of SINEs at orthologous loci support the proposed monophyly of four major groups of cichlid fishes in Lake Tanganyika. Mol Biol Evol 15:391-407

Takahashi K, Nishida M, Yuma M, Okada N (2001a) Retroposition of the AFC family of SINEs (short interspersed repetitive elements) before and during the adaptive radiation of cichlid fishes in Lake Malawi and related inferences about phylogeny. J Mol Evol 53:496-507

Takahashi K, Terai Y, Nishida M, Okada N (2001b) Phylogenetic relationships and ancient incomplete lineage sorting among cichlid fishes in Lake Tanganyika as revealed by analysis of the insertion of retroposons. Mol Biol Evol 18:2057-2066

Taylor MI, Verheyen E (2001) Microsatellite data reveals weak population substructuring in Copadichromis sp. 'virginalis kajose', a demersal cichlid from Lake Malawi, Africa. J Fish Biol 59:593-604

Taylor MI, Ruber L, Verheyen E (2001) Microsatellites reveal high levels of population substructuring in the species-poor Eretmodine cichlid lineage from Lake Tanganyika. Proc R Soc Lond B Biol Sci 268:803-808

Turner GF, Burrows MT (1995) A model of sympatric speciation by sexual selection. Proc R Soc Lond B Biol Sci 260:287-292

Turner GF, Seehausen O, Knight ME, Allender CJ, Robinson RL (2001) How many species of cichlid fishes are there in African lakes? Mol Ecol 10:793-806
Verheyen E, Ruber L, Snoeks J, Meyer A (1996) Mitochondrial phylogeography of rock-dwelling cichlid fishes reveals evolutionary influence of historical lake level fluctuations of Lake Tanganyika, Africa. Philos Trans R Soc Lond B Biol Sci 351:797-805

Verheyen E, Salzburger W, Snoeks J, Meyer A (2003) Origin of the superflock of cichlid fishes from Lake Victoria, East Africa. Science 300:325-329

Wilson AB, Noack-Kunnmann K, Meyer A (2000) Incipient speciation in sympatric Nicaraguan crater lake cichlid fishes: sexual selection versus ecological diversification. Proc R Soc Lond B Biol Sci 267:2133-2141

Woltereck R (1931) Wie entsteht eine endemische Rasse oder Art? Biol Zentralbl 51:231-253

Worthington EB (1937) On the evolution of fish in the Great Lakes of Africa. Int Rev Ges Hydrol Hydrogr 35:304-317

Worthington EB (1940) Geographical differentiation in fresh waters with special reference to fish. In: Huxley $\mathrm{J}$ (ed) The new systematics. Clarendon, Oxford, pp 287-302

Zardoya R, Vollmer DM, Craddock C, Streelman JT, Karl S, Meyer A (1996) Evolutionary conservation of microsatellite flanking regions and their use in resolving the phylogeny of cichlid fishes (Pisces: Perciformes). Proc R Soc Lond B Biol Sci 263:1589-1598 